\title{
3D Multiscale Integrated Modeling Approach of Complex Rock Mass Structures
}

\author{
Mingchao Li, ${ }^{1,2}$ Yanqing Han, ${ }^{2}$ Gang Wang, ${ }^{3}$ and Fugen Yan ${ }^{2}$ \\ ${ }^{1}$ State Key Laboratory of Hydraulic Engineering Simulation and Safety, Tianjin University, \\ Tianjin 300072, China \\ ${ }^{2}$ School of Civil Engineering, Tianjin University, Tianjin 300072, China \\ ${ }^{3}$ Chengdu Design \& Research Institute, Chengdu 410014, China \\ Correspondence should be addressed to Mingchao Li; lmc@tju.edu.cn
}

Received 19 April 2014; Revised 21 June 2014; Accepted 1 July 2014; Published 10 July 2014

Academic Editor: Changchun Hua

Copyright (C) 2014 Mingchao Li et al. This is an open access article distributed under the Creative Commons Attribution License, which permits unrestricted use, distribution, and reproduction in any medium, provided the original work is properly cited.

\begin{abstract}
Based on abundant geological data of different regions and different scales in hydraulic engineering, a new approach of 3D engineering-scale and statistical-scale integrated modeling was put forward, considering the complex relationships among geological structures and discontinuities and hydraulic structures. For engineering-scale geological structures, the 3D rock mass model of the study region was built by the exact match modeling method and the reliability analysis technique. For statistical-scale jointed rock mass, the random network simulation modeling method was realized, including Baecher structure plane model, Monte Carlo simulation, and dynamic check of random discontinuities, and the corresponding software program was developed. Finally, the refined model was reconstructed integrating with the engineering-scale model of rock structures, the statistical-scale model of discontinuities network, and the hydraulic structures model. It has been applied to the practical hydraulic project and offers the model basis for the analysis of hydraulic rock mass structures.
\end{abstract}

\section{Introduction}

At present, a reconstructed 3D geological model in a large regional tectonic range has been applied to analyze rock mass structures for engineering structures widely [1-3], based on abundant initial data such as topographic contours, geological observation points, drills, adits, and remotesensing images. However, there are many other minor-scale random structures such as discontinuities in rock masses. A complicated system of rock mass structures is combined with these minor-scale structures and some major-scale geological structures such as strata, faults, and weak layers. They control and influence the stability of foundation engineering, underground engineering, and slope engineering [4].

Then, the rock mass environment in the engineering region can be represented together by multiscale data, from determinate geological structures by exploration and statistical data of discontinuities by field investigation. It is important to solve practical problems of engineering geology that two kinds of data should be integrated into a whole model effectively. There are several relevant modeling approaches about the problem. Zhang [5] built different scale models to analyze rock quality evaluation and slope stability. Aitken and Betts [6] simulated the geological structures of an actual area using the multiscale structural and aeromagnetic analysis method. Jones et al. [7] developed a 3D geospatial system to combine all kinds of geological and geophysical data sources from outcrop to regional scale into a single model. $\mathrm{Xu}$ [8] built a hierarchical rock mass structure model (RSM) to deal with the problem. These results are pertinent for various geological data from different sources.

This paper presents a new 3D modeling approach integrating major engineering-scale geological structures with minor statistical-scale data of discontinuities. The reconstructed refined geoengineering model can describe discontinuous structures into rock masses in depth and actual geological environment objectively. 


\section{Multiscale Classification of Complex Rock Mass Structures}

Geological boundaries with a certain direction and extension are collectively referred to as structural surfaces, including substance differentiation surfaces (such as horizons, schistosities, weak intercalated layers, and intrusions) and discontinuous fractured planes (such as faults, joints and weathering or relief fissures). Then, corresponding rock masses are constrained by these different combined structural surfaces, which are dominant.

In the field of geotechnical engineering, structural surfaces are classified into five levels, that is, I, II, III, IV, and V $[5,9]$. They can be divided into four spatial scales.

(1) Regional-scale structures corresponding to levels I and II, such as regional faults: they may affect the region stability with hundreds of kilometers extension.

(2) Engineering-scale structures corresponding to level III, such as horizons, weak layers, and faults: they extend from hundreds to thousands of meters with good continuity and a certain thickness. And they may destruct the continuity and stability of rock masses.

(3) Statistical-scale structures corresponding to level IV, such as horizons, weak layers, and faults: they extend from several to tens of meters with random discrete distributions and statistical-advantaged directions. And they may affect the deformation mode of rock masses and result in anisotropic rock mechanical properties. Due to lack of determined spatial information, they may be described by statistical models with certain probability distribution and are called statistical-scale geological data.

(4) Sample-scale structures corresponding to level V, such as hidden microcracks: their length level is about millimeter or centimeter. They are short and close with random discrete distributions. And they may decrease the rock strength.

Among the four structures, engineering-scale and statistical-scale data are emphases in hydraulic engineering geology, as shown in Figure 1. Generally, major engineering-scale data are acquired by geological exploration of drills and adits and interpreted to different cross-sections, while minor statistical-scale data are drawn to geolograph charts from field discontinuities. Then, according to their data features, we will use different methods to build two kinds of models and realize their integration effectively.

\section{3D Modeling of Major Engineering-Scale Structures}

The regional engineering-scale geological data of hydraulic projects mainly include topographic contours, geological points, remote sensing images, drills, adits, and geophysical information. They can be interpreted to a variety of 2D crosssections by geological engineers. All these data are the basis of reconstructing $3 \mathrm{D}$ models.

The general structure of 3D modeling of major engineering-scale rock mass structures is shown in Figure 2. Firstly, based on multisource geological data and engineering design data, geological objects are classified into terrain, horizons, and faults, while engineering objects are divided into dam structure, underground tunnels, and drills and adits by the object-oriented technique. Secondly, corresponding 3D models of geological and engineering structures are built by enhanced NURBS (Nonuniform Rational B-Spline) modeling method [1]. During the process, the models must be verified and revised using the original exploration data. The verification includes checks of topological geometry, structural rationality, and accuracy tests on raw data [1]. Finally, the integrated geoengineering model is completed through a series of complex 3D Boolean operations.

\section{3D Stochastic Modeling of Minor Statistical-Scale Jointed Rock Mass Network}

All kinds of stochastic discontinuities are distributed in rock masses widely. And they may control the strength and deformation of rock masses and are named jointed rock mass network system. It is defined by International Society for Rock Mechanics [10] that a variety of mechanical jointed surfaces or zones grow in rock structures, such as minor faults, weak belts, and joints.

According to many results from field survey, discontinuities are so numerous that it is difficult to discover the geometric and mechanical properties of each individual. However, due to their randomness and irregularity, their critical parameters can be assumed to stochastic variables and described by probability and stochastic models based on plenty of measured data. Then, 3D stochastic simulation technique of structural plane network was put forward to analyse their distribution rules.

Priest and Samaniego [11] built the 2D model of discontinuous rock structures using the random statistical method. Kulatilake et al. [12] estimated joint geometry parameters and completed the 3D joint network model based on statistical homogeneity investigation, sample correction, and stereological method. Zhou et al. [13] put forward a self-coordinated approach to generate the $3 \mathrm{D}$ fracture network model by the measured 2D data. Li et al. [14] developed the generation and visualization system of 3D stochastic structural planes using the Poisson random process. Turanboy et al. [15] realized the $3 \mathrm{D}$ visualization of landslide discontinuities based on the acquired exploration data. Dowd et al. [16] cut the actual granite into layers and obtained true three-dimensional fracture network data sets through direct measurement and analysis. Pan et al. [17] built the 3D fracture model with crack permeability tensor to analyze the flow and transport in fractured rock.

Therefore, the jointed network simulation approach analyses actual measured data to obtain their statistical parameters of the occurrence, interval, and density and then generate geometric models based on the probability model 


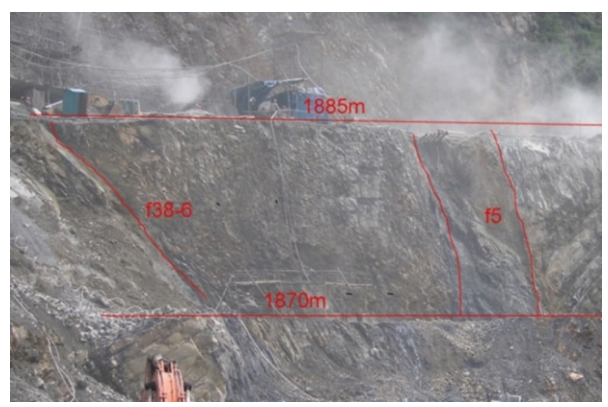

(a)

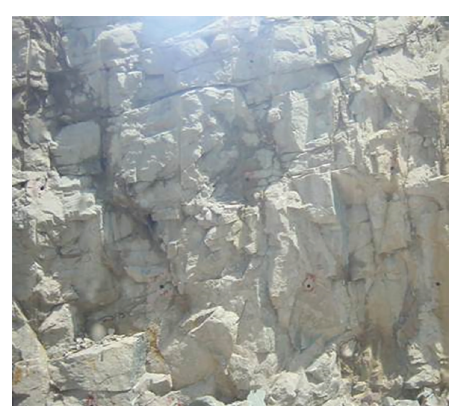

(b)

FIGURE 1: Two critical types of rock mass structures in hydraulic engineering. (a) Major engineering-scale geological structures. (b) Minor statistical-scale discontinuities.

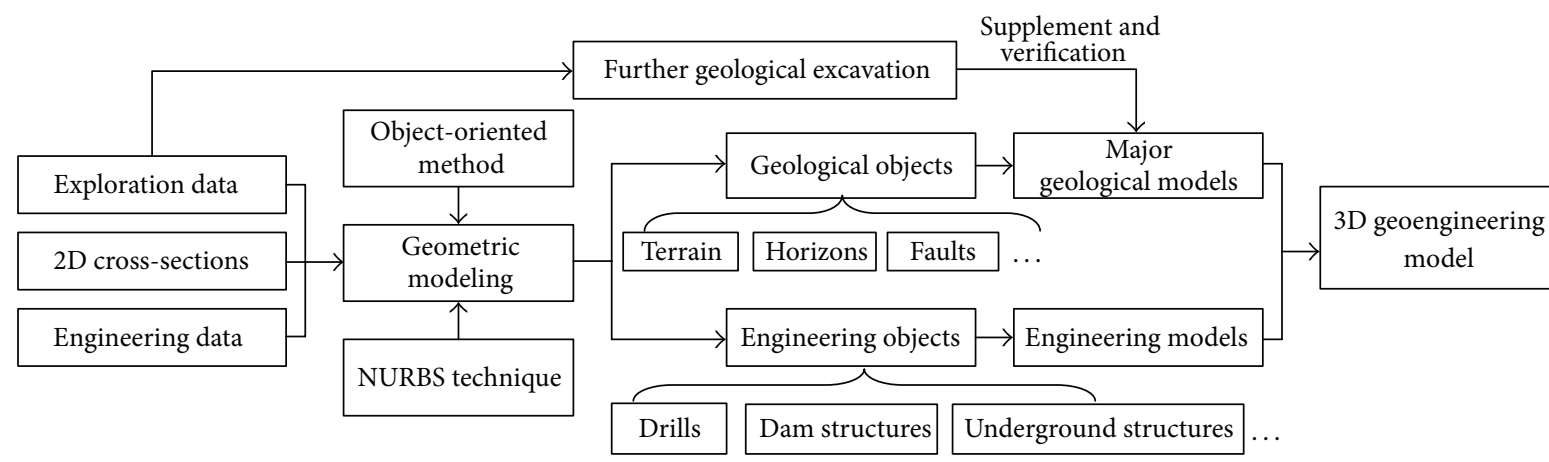

FIGURE 2: 3D geological modeling general framework of engineering-scale structures.

and certain simulation method. We adopted Baecher's disk model [18] and Monte Carlo simulation technique to realize the stochastic simulation modeling of jointed rock mass network, while the above engineering-scale geological mode provides the reliable boundary.

4.1. Baecher's Disk Model. This model was developed by Baecher et al. [18] and the fractures are defined as "bounded planar features of random size and orientation, randomly positioned in three-dimensional space" [19]. The fundamental assumptions of the model are listed as follows.

AS1: joints are circular 2D disks.

AS2: the center points of joints are randomly and independently distributed in space forming a Poisson field.

AS3: the radii of joints are lognormally distributed.

AS4: joint radius and dip are uncorrelated (statistically independent).

AS5: joint radius and spatial location are uncorrelated (statistically independent).

Then, the size and location of a circular fracture can be defined by three critical parameters, that is, the central point $O\left(x_{0}, y_{0}, z_{0}\right)$, the radius $R$, and the occurrence $V(\alpha, \beta)$. Baecher's disk model has been most extensively used for rock mechanics studies, for it is conceptually simple and applicable, and the corresponding numerical analysis will be relatively easy.
4.2. 3D Simulation of Stochastic Jointed Network. Based on Baecher's model and the corresponding assumptions, 3D simulation of stochastic jointed network can be realized by the following steps.

(1) Define valid simulated subregions. Its size is determined by homogeneous sampling subregions and engineering requirements. Due to inhomogeneity of stochastic discontinuities, there are multiple homogeneous subregions in the engineering region. For example, there are $n$ subregions in the whole engineering region $\Omega$, and one subregion is $\Omega_{i}(i=$ $1,2, \ldots, n)$. The corresponding simulated subregion $M_{i}$ to $\Omega_{i}$ is defined by the minimum bounding box algorithm:

$$
M_{i}=\left\{\begin{array}{l}
X_{\min } \leq x \leq X_{\max } \\
Y_{\min } \leq y \leq Y_{\max } \\
Z_{\text {min }} \leq z \leq Z_{\max }
\end{array}\right.
$$

where $\left(X_{\min }, Y_{\min }, Z_{\min }\right)$ and $\left(X_{\max }, Y_{\max }, Z_{\max }\right)$ are the minimum and maximum coordinates of $\Omega_{i}$. Then, $\Omega_{i}$ may be irregular, while $M_{i}$ must be a rectangular solid, and $\Omega_{i} \subseteq M_{i}$.

(2) Simulate structural plane parameters of jointed network. This process is opposite to the field measurement and statistics. Here the Monte Carlo simulation method is adopted. According to obtained 
distribution functions of different stochastic variables, random numbers with uniform distribution are generated by algorithm. Then structural plane parameters can be simulated to satisfy measured distribution functions by random sampling from generated random numbers.

(3) Generate jointed structural planes. Based on the assumption of random uniform distribution for structure planes, three stochastic values of their central points $\left(x_{i 0}, y_{i 0}, z_{i 0}\right)$ are independent and uniformly distributed. If $r_{1 i}, r_{2 i}, r_{3 i}$ are independent random numbers of standard uniform distribution, then the central point $O_{i}\left(x_{i 0}, y_{i 0}, z_{i 0}\right)$ of the structure plane $D_{i}$ can be calculated:

$$
\begin{gathered}
x_{i 0}=X_{\text {min }}+\left(X_{\text {max }}-X_{\text {min }}\right) r_{1 i} \\
y_{i 0}=Y_{\text {min }}+\left(Y_{\text {max }}-Y_{\text {min }}\right) r_{2 i} \\
z_{i 0}=Z_{\text {min }}+\left(Z_{\text {max }}-Z_{\text {min }}\right) r_{3 i} .
\end{gathered}
$$

Although (2) can ensure that the plane $D_{i}=f\left(O_{i}, V_{i}, R_{i}\right)$ locates in the region $M_{i}, \Omega_{i} \subseteq M_{i}$, and we need to compute the spatial relationship between $O_{i}$ and $\Omega_{i}$ to decide its validity.

4.3. Verification of Simulated Results. The simulated results can be in accordance with the measured data statistically, but there are some differences with the sampling region. To improve the accuracy, the model should be checked, verified, and revised. We set up three verification principles based on the measured discontinuities from statistics. (1) Verify that the measured and simulated discontinuities belong to the same group to ensure that their occurrences are similar. (2) Verify the nearest measured and simulated discontinuities from center points to ensure their consistent distribution features. (3) Verify all outcropped discontinuities in the sampling region.

\section{Multiscale Model Integration and Application}

5.1. Integrated Modeling Process. Considering geological structures, discontinuities, hydraulic structures, and their complicated relationship, the multiscale integrated mathematical model is set up based on NURBS modeling [20] as follows:

$$
\begin{gathered}
M_{\Omega}=\bigcup_{i=1}^{n_{1}} M_{c_{i}} \oplus \bigcup_{j=1}^{n_{2}} M_{d_{j}} \oplus \bigcup_{k=1}^{m} M_{e_{k}}, \\
M_{c_{i}}=S_{i 1} \cup S_{i 2} \cup\left(\bigcup_{l=1}^{q_{i}} S l_{i l}\right), \quad i=1,2, \ldots, n_{1}, \\
M_{d_{j}}=f\left(O_{j}, V_{j}, R_{j}\right), \quad j=1,2, \ldots, n_{2}, \\
M_{e_{k}}=F\left(d_{p 1}, d_{p 2}, \ldots\right), \quad k=1,2, \ldots, m,
\end{gathered}
$$

TABLE 1: Characteristic parameters of simulated random structural planes.

\begin{tabular}{lccc}
\hline Parameters & \multicolumn{3}{c}{ Group } \\
& NE & NWW & NW \\
\hline AVG. $R$ & 14.0 & 19.6 & 14.8 \\
STDEV. $R$ & 10.2 & 5.7 & 6.4 \\
AVG. Dip direction & 80.3 & 294.5 & 344.1 \\
AVG. Dip angle & 65.9 & 67.5 & 88.3 \\
\hline
\end{tabular}

$$
\begin{gathered}
S_{i x}=s\left(\mathbf{P}_{i x}\right), \quad i=1,2, \ldots, n_{1} ; x=1,2, \\
S l_{i l}=s^{\prime}\left(\left\{v_{i l}\right\}\right), \quad v_{i l} \in \partial S_{i 1} \cup \partial S_{i 2}, \\
i=1,2, \ldots, n_{1} ; \quad l=1,2, \ldots, q_{i}
\end{gathered}
$$

where $\Omega$ is the whole study region; $M_{\Omega}$ is the whole geological model of $\Omega ; n_{1}, n_{2}$, and $m$ are the total number of rock structures, simulated jointed planes, and hydraulic structures; $M_{c i}$ is the $i$ th rock structure body, which is built by two major structural surfaces of $S_{i 1}, S_{i 2}$, and $q_{i}$ peripheral surfaces $S l_{i l}$ connecting $S_{i 1}$ and $S_{i 2} ; S_{i 1}$ and $S_{i 2}$ are the NURBS surfaces fitted by their point sets $\mathbf{P}_{i x}, \mathbf{P}_{i 2} ; \partial S_{i 1}$ and $\partial S_{i 2}$ are the set of all bounding vertexes of $S_{i 1}$ and $S_{i 2} ; M_{d j}$ is the $j$ th jointed plane which is simulated through parametric modeling method with its center point $O_{j}$, occurrence $V_{j}$, and radius $R_{j} ; M_{e k}$ is the $k$ th hydraulic structure submodel by some design parameters.

According to the principle of spatial subdivision, any object with complex geometry may be reconstructed by (3). Each geological body is enclosed by six boundary surfaces of top and bottom, front and back, and left and right. When all kinds of geological structures are simulated using the proposed approach, the whole geological model can be reconstructed by geometric operations. For example, a horizon body is formed by $3 \mathrm{D}$ Boolean operations among NURBS surfaces of top, bottom, and topographic body.

5.2. Case Analysis. The proposed approach was applied to a hydropower project with complicated geological conditions. The project is a pumped storage power station, including upper and lower reservoirs, main and auxiliary dams, water transport tunnels, and the underground powerhouse. The geological structures of this area are complex due to great variability in lithology, intensive tectonic deformation, and abundant fractures. In the current study, the proposed approach was used to model the project's geological information with a primary focus on the underground powerhouse area.

Based on the multisource data from the geological exploration and interpretation, the actual geoengineering model of the project region was reconstructed as shown in Figure 3. The models contain several rock units $\left(\mathrm{S}_{3 \mathrm{~m}}{ }^{3-1}, \mathrm{~S}_{3 \mathrm{~m}}{ }^{3-2}\right.$, and $\mathrm{S}_{3 \mathrm{~m}}{ }^{3-3}$ are different quartz sandstones), Quaternary overburden (Qs), some faults related with the project, and main hydraulic structures such as the dams, the upper reservoir, and the underground tunnels group. 


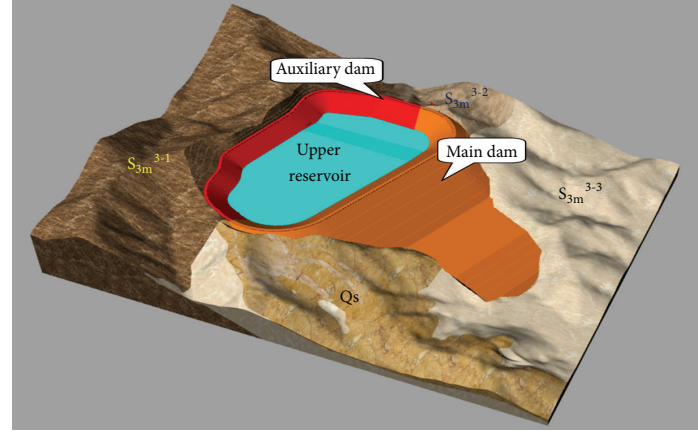

(a)

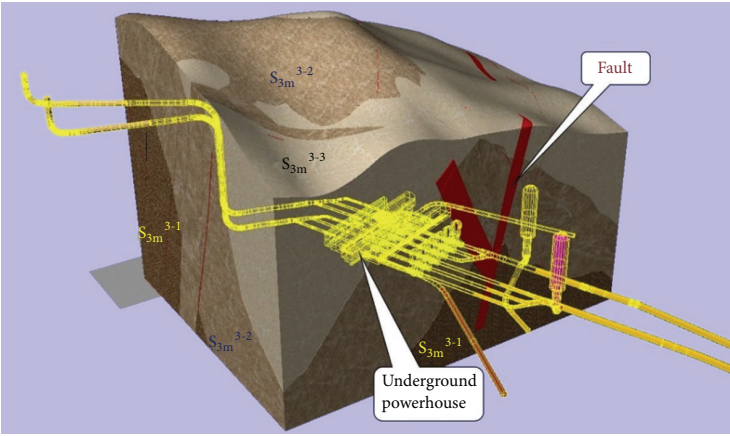

(b)

FIGURE 3: Practical 3D geoengineering models with major geological structures and hydraulic engineering structures. (a) Model in the dam region. (b) Model in the underground powerhouse region.

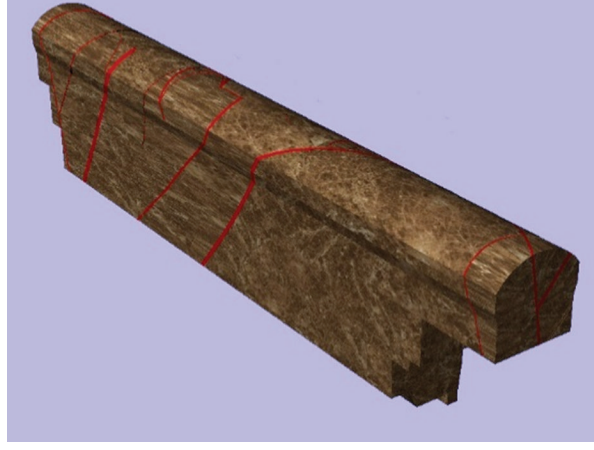

(a)

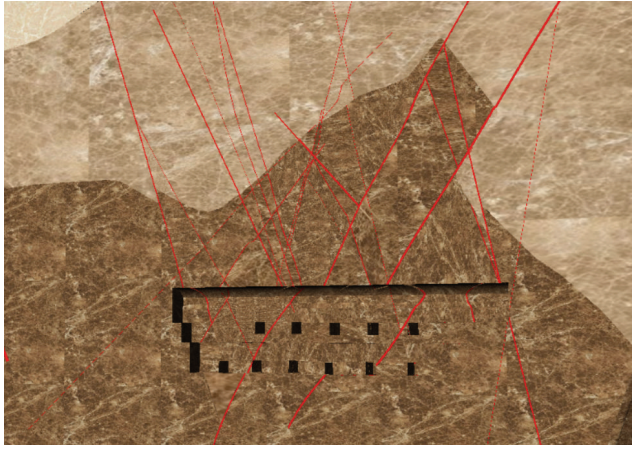

(b)

FIGURE 4: 3D models of the studied powerhouse region. (a) Geological model of the main powerhouse. (b) Geological section along the axis of the main powerhouse.

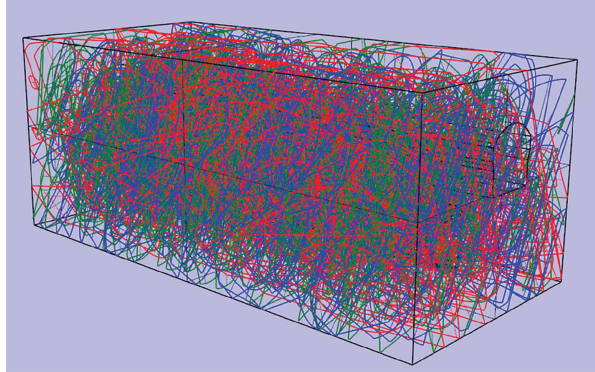

(a)

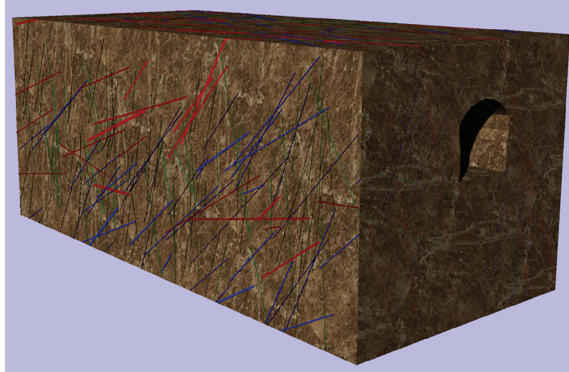

(b)

FiguRE 5: 3D integrated mode with minor discontinuities. (a) 1557 simulated discontinuities in the powerhouse region. (b) 3D multiscale model of rock mass structures with the powerhouse.

The length, width, and height of the underground power station are $219.9 \mathrm{~m}, 23.5 \mathrm{~m}$, and $55.3 \mathrm{~m}$, respectively, as shown in Figure 4. The rock formation of this area includes $S_{3 m}{ }^{3-1}$ rocks, a few faults, and many discontinuities.

The dominant occurrences of the discontinuities in the studied region were divided into three groups, as shown in Table 1. Totally 1557 planes were simulated as shown in Figure 5(a). Integrating these discontinuities with the major geological structures and the main powerhouse, the multiscale model could be obtained by $3 \mathrm{D}$ Boolean operations, as shown in Figure 5(b), which described the distribution of complex rock mass and discontinuities. They would offer useful supports for rock mass structure analysis of civil engineering, such as rock mass quality classification, landslide stability assessment, and critical blocks identification.

\section{Conclusions}

According to the multiscale data of rock mass structures from different regions, this paper put forward different 3D 
modeling and integrated modeling methods, cohering with geologic accuracy, structural continuity, and data storage.

(1) For major engineering-scale geological structures, some techniques including hybrid data structure based on NURBS, classified objects modeling method, and exact matching algorithm were used to reconstruct the $3 \mathrm{D}$ geoengineering model of the whole region. The model could also offer the boundaries for discontinuities.

(2) For minor statistical-scale discontinuities, the 3D stochastic modeling approach of discontinuities network was proposed based on measured data and related statistical analysis. The approach consists of Baecher's disk model, Monte Carlo simulation of discontinuities network, and model verification, and the realized program module has been developed.

(3) Considering the complicated relationship among geological structures, stochastic discontinuities, and hydraulic structures, the integrated mathematical model was built with major engineering-scale and minor statistical-scale structures. And it was applied to an actual hydraulic project and the multiscale model of the powerhouse region was completed.

Then, next emphasis is that the model should be applied to engineering practices, such as rock mass classification, stability analysis, and seepage analysis, while it would be revised and improved in practice.

\section{Conflict of Interests}

The authors declare that there is no conflict of interests regarding the publication of this paper.

\section{Acknowledgments}

This research was supported by the National Natural Science Foundation of China (Grant nos. 51379006, 51021004), the National Basic Research Program of China (973 Program) (Grant no. 2013CB035903), and the Program for New Century Excellent Talents in University of Ministry of Education of China (Grant no. NCET-12-0404).

\section{References}

[1] D.-H. Zhong, M.-C. Li, L.-G. Song, and G. Wang, "Enhanced NURBS modeling and visualization for large 3D geoengineering applications: an example from the Jinping first-level hydropower engineering project, China," Computers \& Geosciences, vol. 32, no. 9, pp. 1270-1282, 2006.

[2] R. Hack, B. Orlic, S. Ozmutlu, S. Zhu, and N. Rengers, “Three and more dimensional modelling in geo-engineering," Bulletin of Engineering Geology and the Environment, vol. 65, no. 2, pp. 143-153, 2006.

[3] S. R. Sun, Y. X. Lu, Y. Y. Xu, J. Liu, and J. H. Wei, "Study on analog theory of rock mass simulation and its engineering application," Mathematical Problems in Engineering, vol. 2013, Article ID 491069, 11 pages, 2013.
[4] R. E. Goodman, Introduction to Rock Mechanics, John Wiley \& Sons, New York, NY, USA, 2nd edition, 1989.

[5] F. M. Zhang, Multi-Scale Geometric Simulation of Geological Structures and Applications, Science Press, Beijing, China, 2007.

[6] A. R. A. Aitken and P. G. Betts, "Multi-scale integrated structural and aeromagnetic analysis to guide tectonic models: an example from the eastern Musgrave Province, Central Australia," Tectonophysics, vol. 476, no. 3-4, pp. 418-435, 2009.

[7] R. R. Jones, K. J. W. McCaffrey, P. Clegg et al., "Integration of regional to outcrop digital data: $3 \mathrm{D}$ visualisation of multi-scale geological models," Computers \& Geosciences, vol. 35, no. 1, pp. $4-18,2009$.

[8] N. X. Xu, "Identifying rock blocks based on hierarchical rockmass structure model," Science in China D: Earth Sciences, vol. 52, no. 10, pp. 1612-1623, 2009.

[9] D. Z. Gu, Geological Mechanics Foundation of Rock Engineering, Science Press, Beijing, China, 1979.

[10] ISRM, Rock Characterization, Testing and Monitoring, ISRM Suggested Methods, Pergamon Press, Oxford, UK, 1981.

[11] S. D. Priest and A. Samaniego, "A model for the analysis of discontinuity characteristics in two dimensions," in Proceedings of the 5th International Congress on Rock Mechanics, pp. 199-207, Melbourne, Australia, 1983.

[12] P. H. S. W. Kulatilake, D. N. Wathugala, and O. Stephansson, "Joint network modelling with a validation exercise in Stripa mine, Sweden," International Journal of Rock Mechanics and Mining Sciences \& Geomechanics Abstracts, vol. 30, no. 5, pp. 503-526, 1993.

[13] W. Y. Zhou, R. G. Yang, J. M. Yin, and Z. R. Wang, "Three dimensional joint network in rockmass using self-adjusted method and engineering application," Chinese Journal of Rock Mechanics and Engineering, vol. 16, no. 1, pp. 29-35, 1997.

[14] X. Li, S. Yang, and X. Wang, "Generation and visualization technologies of three-dimensional network of rockmass stochastic structural plane," Chinese Journal of Rock Mechanics and Engineering, vol. 26, no. 12, pp. 2564-2569, 2007.

[15] A. Turanboy, M. K. Gökay, and E. Ülker, "An approach to geometrical modelling of slope curves and discontinuities," Simulation Modelling Practice and Theory, vol. 16, no. 4, pp. 445461, 2008.

[16] P. A. Dowd, J. A. Martin, C. Xu, R. J. Fowell, and K. V. Mardia, "A three-dimensional fracture network data set for a block of granite," International Journal of Rock Mechanics and Mining Sciences, vol. 46, no. 5, pp. 811-818, 2009.

[17] J. Pan, C. Lee, C. Lee, H. Yeh, and H. Lin, "Application of fracture network model with crack permeability tensor on flow and transport in fractured rock," Engineering Geology, vol. 116, no. 1-2, pp. 166-177, 2010.

[18] G. B. Baecher, N. A. Lanney, and H. H. Einstein, "Statistical description of rock properties and sampling," in Proceeding of the 18th U.S. Symposium on Rock Mechanics (USRMS '77), pp. 501-508, Golden, Colo, USA, 1977.

[19] G. B. Baecher, "Statistical analysis of rock mass fracturing," Journal of the International Association for Mathematical Geology, vol. 15, no. 2, pp. 329-348, 1983.

[20] D. H. Zhong and M. C. Li, Theories and Applications of 3D Engineering-Geological Modeling and Analysis to Hydraulic and Hydroelectric Projects, China Water Power Press, Beijing, China, 2006. 


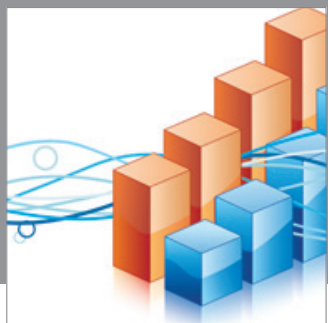

Advances in

Operations Research

mansans

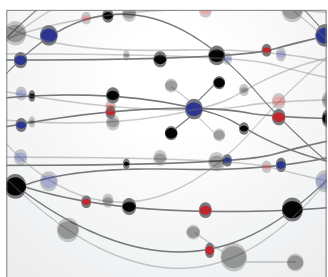

The Scientific World Journal
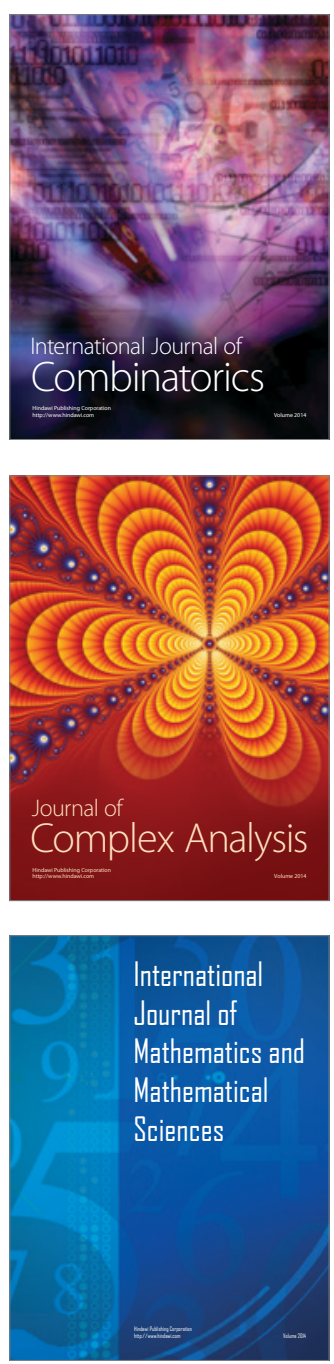
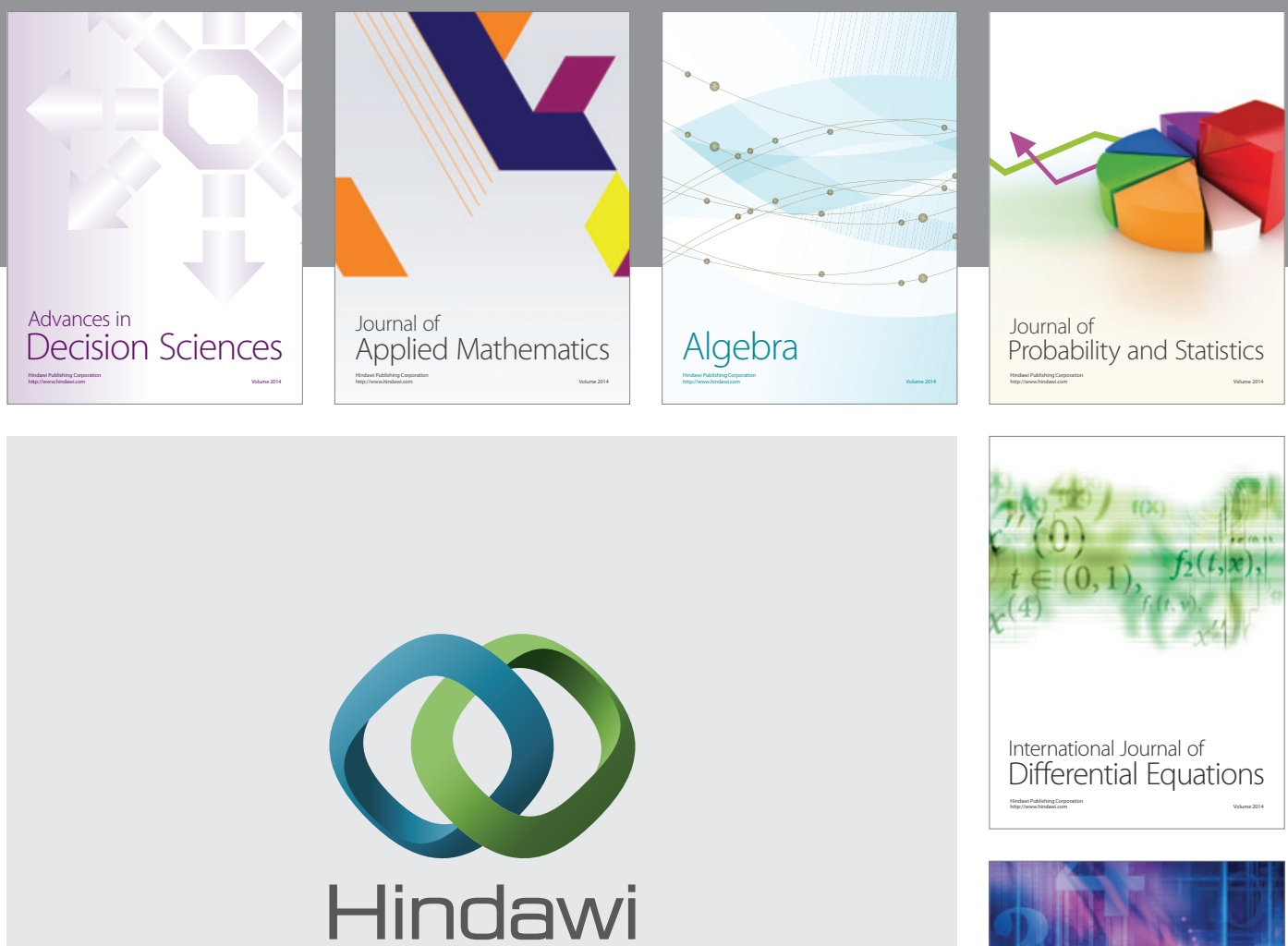

Submit your manuscripts at http://www.hindawi.com
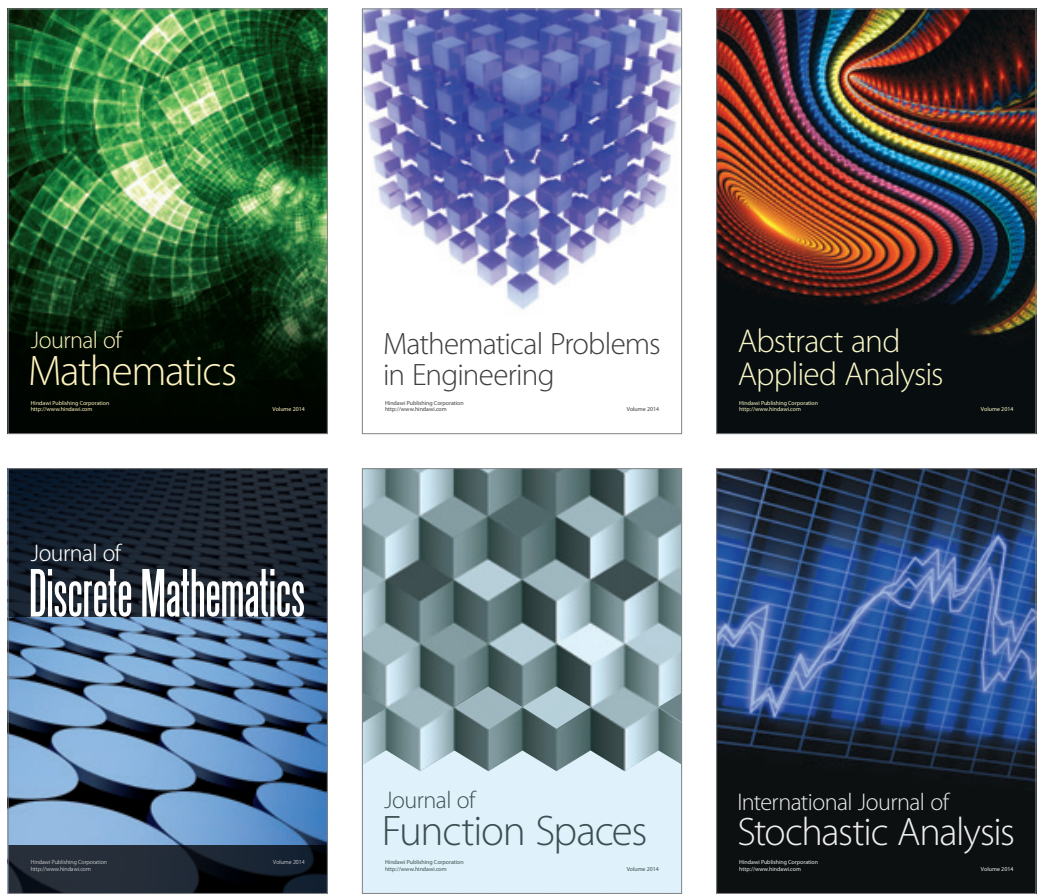

Journal of

Function Spaces

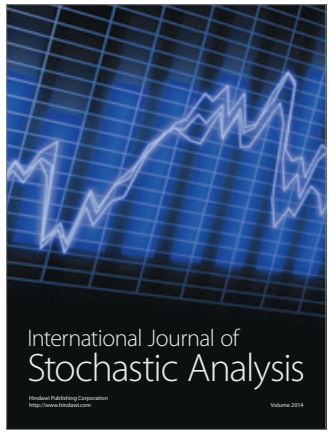

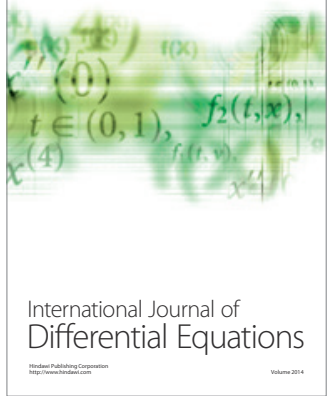
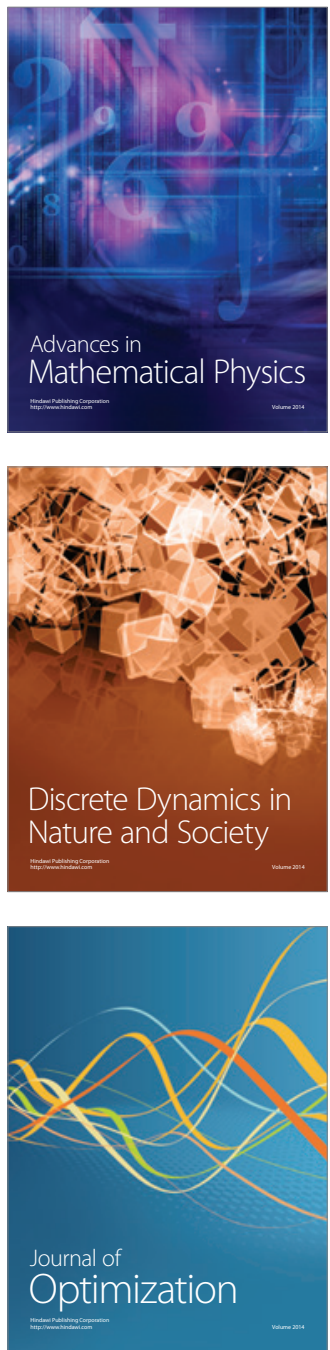